TI 2013-096/VII

Tinbergen Institute Discussion Paper
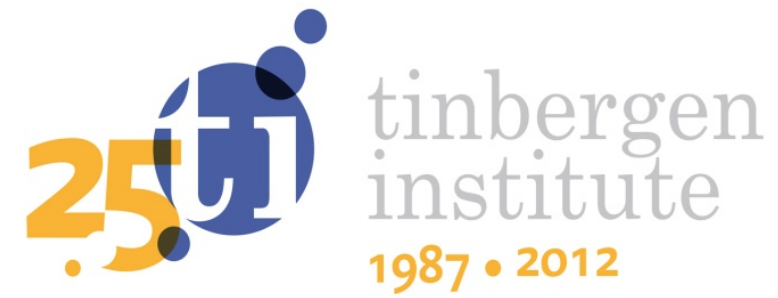

\title{
The Economics of First-Contract Mediation
}

Sabien Dobbelaere ${ }^{1,2,3}$

Roland Iwan Luttens 1,4

1 Faculty of Economics and Business, VU University Amsterdam,

2 Tinbergen Institute, The Netherlands;

3 IZA, Germany;

4 Amsterdam University College, Amsterdam, The Netherlands. 
Tinbergen Institute is the graduate school and research institute in economics of Erasmus University Rotterdam, the University of Amsterdam and VU University Amsterdam.

More TI discussion papers can be downloaded at http://www.tinbergen.nl

Tinbergen Institute has two locations:

Tinbergen Institute Amsterdam

Gustav Mahlerplein 117

1082 MS Amsterdam

The Netherlands

Tel.: +31(0)205251600

Tinbergen Institute Rotterdam

Burg. Oudlaan 50

3062 PA Rotterdam

The Netherlands

Tel.: +31(0)10 4088900

Fax: $+31(0) 104089031$

Duisenberg school of finance is a collaboration of the Dutch financial sector and universities, with the ambition to support innovative research and offer top quality academic education in core areas of finance.

DSF research papers can be downloaded at: http://www.dsf.nl/

Duisenberg school of finance

Gustav Mahlerplein 117

1082 MS Amsterdam

The Netherlands

Tel.: +31(0)20 5258579 


\title{
The economics of first-contract mediation*
}

\author{
Sabien DOBBELAERE $\quad$ Roland Iwan LUTTENS ${ }^{\ddagger}$
}

July, 2013

\begin{abstract}
This paper provides an economic foundation for non-binding mediation to stimulate first collective bargaining agreements, as implemented in British Columbia since 1993. We show that the outcome of firstcontract mediation is Pareto efficient and proves immune to the insider-outsider problem of underhiring. We also demonstrate that equilibrium wages and profits under mediation coincide with the Owen values of the corresponding cooperative game with the coalitional structure that follows from unionization.
\end{abstract}

JEL classification: C71, J51, L20, K12.

Keywords : BC first-contract model, mediation, collective bargaining, union, non-binding contract.

\section{Introduction}

For decades, obtaining a first collective bargaining agreement has been a major hurdle for the US union movement. Ferguson and Kochan (2008) demonstrate that between 1999 and 2004, only 38\% of newly certified unions succeeded in reaching such an agreement within one year, and only $56 \%$ within two years, thereby confirming earlier evidence on first-contract success rates in the US (e.g. Cooke, 1985). Reasons for bargaining failure include an immature context of the bargaining relationship, inexperienced negotiators, unrealistic union expectations and a set of both legal and illegal firm strategies to oppose unionization (Johnson, 2010). The inherent difficulty of resolving first collective bargaining agreements leads to greater labor turnover, higher employee dissatisfaction, increased risk of union decertification and the creation of a multi-million dollar industry of consultants and lawyers specialized in stalling negotiations.

To remedy these problems, the US Employee Free Choice Act stipulates that the National Labor Relations Board provides for first-contract arbitration (FCA). If negotiations drag on without resolution, the dispute is referred to an arbitration panel empowered to determine a collective first agreement which is binding for at least two years. The prospect of a third party making contract decisions incentivizes unions and employers to reach an agreement on their own. Using a panel of ten Canadian jurisdictions that introduced FCA over the period 1976-2005, Johnson (2010) finds that FCA encourages collective bargaining without resorting to arbitration in the sense that the average likelihood of an imposed contract is only $5 \% .^{1}$ In addition, FCA reduces work stoppage incidence by at least 50 percent.

\footnotetext{
${ }^{*}$ We are grateful to Bart Cockx, Pieter Gautier, Harold Houba, Philipp Kircher and Glenn Rayp for helpful comments and suggestions.

${ }^{\dagger}$ VU University Amsterdam, Tinbergen Institute and IZA.

${ }^{\ddagger}$ Amsterdam University College and VU University Amsterdam.

${ }^{1}$ Canadian labor laws relating to industrial relations are modeled on US labor law.
} 
However, it remains unclear whether FCA truly contributes to voluntary bargaining rather than forcing the bargaining parties to act, often involuntarily, just in anticipation to arbitration. To stimulate the voluntary bargaining process, the province of British Columbia (BC) introduced in 1993 a powerful mediation procedure prior to arbitration. The centerpiece of the $\mathrm{BC}$ first-contract model is non-binding mediation wherein the issued recommendations regarding the terms of the collective first agreement can be rejected by either party. Furthermore, mediation is bound by the replication principle. This implies that the mediator's objective is to replicate a collective bargaining agreement which reflects as nearly as possible the collective bargaining agreement that conventional bargaining between the parties would have produced. Assessing the BC firstcontract model, Vipond (2011) provides qualitative evidence on its success to resolve first-contract disputes voluntarily and to foster enduring bargaining relationships. Her interview data convey broad satisfaction on behalf of employers, unions, as well as mediators and arbitrators. Given its success and given the similarities between Canadian and US labor laws, an increasing number of policy makers and scholars consider the BC first-contract model viable for the US.

Until now, a discussion of the merits of first-contract mediation has been confined to the labor law literature. To the best of our knowledge, an economic analysis of the BC first-contract model has not yet been performed. This paper aims at filling this gap. We present a theoretical framework which captures non-binding mediation under the replication principle. The mediator in our model is not an economic agent, who extracts part of the rents on the bargaining table. That would be in violation with the replication principle. The unique feature of our model is that mediation changes the structure of the non-cooperative bargaining game between the union and the firm. Traditionally, it is common to model collective bargaining as a single alternating-offer bargaining game with exogenous breakdown probabilities in which all employed union members return to the external labor market when negotiations fail. Under mediation, both parties are free to engage in an arbitrary number of pairwise negotiations because recommendations - mimicking bargaining outcomes- are non-binding. Since contracts are non-binding, any number of dissatisfied workers are free to quit and/or the firm is free to dismiss any number of individual workers after each negotiation. Hence, non-binding mediation is modeled as a finite sequence of alternating-offer bargaining games. We are looking for the mediation contract that is $(i)$ non-wasteful, in the sense that all rents from production are divided between the union and the firm, (ii) stable, in the sense that neither the union nor the firm can respectively improve wages or profits in further pairwise renegotiations and ( $\mathrm{iii}$ ) incentive compatible, in the sense that the employees' outside option constraint is not violated.

Our pronounced result is that first-contract mediation yields a Pareto-efficient outcome. This result differs from the two settings closest to ours in which unions and firms negotiate over wages, i.e. collective bargaining under binding contracts and individual bargaining under non-binding contracts, which both yield Pareto inefficient outcomes. Furthermore, we show that the availability and the size of a finite replacement pool does not affect the wage-employment equilibrium under first-contract mediation. Finally, we provide a cooperative characterization of our results and demonstrate that our non-cooperative equilibrium wages and profits coincide with the Owen values of the cooperative game with the coalitional structure that follows from unionization.

We believe that our efficiency result offers a powerful economic foundation for the BC first-contract model. First-contract mediation proves immune to the insider-outsider problem of underhiring and the welfare gains associated with the optimal allocation of labor are substantial. These arguments provide a rationale for amending US first-contract legislation towards a stronger mediation-based approach. 
We proceed as follows. Section 2 relates our analysis to traditional models of collective and individual workerfirm bargaining. Section 3 derives the equilibrium mediation contract, shows that it is Pareto efficient and investigates the role of a replacement pool. The cooperative characterization of equilibrium wages and profits is provided in Section 4. Section 5 concludes.

\section{Relation to existing literature}

As a benchmark, consider a neoclassical (NC) (non-bargaining) firm that writes binding contracts with its workers at the reservation wage. The properties of two binding equilibrium wage-employment contracts are widely known in the collective bargaining literature. The right-to-manage bargaining (RTM) model postulates that the union bargains with the firm over wages (Nickell and Andrews, 1983). Compared to the NC firm, underemployment emerges. The union and the firm agree on a Pareto-inefficient contract. To obtain Pareto efficiency, the efficient bargaining (EB) model requires that the union and the firm negotiate simultaneously over wages and employment (McDonald and Solow, 1981). Under the assumption of a risk-neutral union, the underemployment result of the RTM model disappears.

Stole and Zwiebel (SZ) (1996a, 1996b) formalize intrafirm wage bargaining between the firm and its individual risk-neutral employees who are irreplaceable and cannot be contractually tied to the firm. In equilibrium, the SZ firm overhires relative to the NC firm to such an extent that bargained wages are driven down to the reservation wage. Extending the SZ analysis, de Fontenay and Gans (FG) (2003) introduce an outside pool of ready-to-employ replacement workers. Such a finite pool makes it no longer optimal for the firm to overemploy. Moreover, insiders still capture a wage rent since losing an employee brings the firm closer to running out of replacement workers. Therefore, the FG firm underhires relative to the NC firm. Whereas SZ and FG study individual wage bargaining in a non-binding contract setting, Westermark (2003) shows that in a binding contract setting individual wages are competitive and hence employment coincides with the NC firm.

Our paper contributes to the collective bargaining literature by investigating how unionization affects equilibrium wages and profits under mediation, i.e. by changing the contract setting from binding to non-binding. Consistent with the SZ bargaining environment, our analysis enables to verify whether the SZ overemployment and the FG underemployment results are robust to unionization.

\section{First-contract mediation}

\subsection{Model}

We present a discrete version of the model, but results easily extend when labor is assumed to be continuous. Consider a fixed-size union of $\mathcal{N} \in \mathbb{N}$ members. A subset of $n$ union members (the employees) work in the firm. We assume that the union is sufficiently large to cover labor demand $(n \leq \mathcal{N})$. We endogenize the choice of $n$ later on. Wages are generically denoted by $w$. The reservation wage is $\underline{w}$. We denote $\tilde{w}(n)$ the employee's wage in our non-binding setting when there are $n$ employees. The firm utilizes a single asset, increasing and diminishing returns production function $F(n): \mathbb{N} \rightarrow \mathbb{R}_{+}$. We assume that $F(i) \geq i \underline{w}$ for $i \in\{1, \ldots, n\}$ for reasons of incentive compatibility that will become clear later on. Denote $\Delta F(n) \equiv F(n)-F(n-1)$ the first difference operator. The profit function is generically denoted by $\pi(n): \mathbb{N} \rightarrow \mathbb{R}$. The neoclassical firm's 
profit function equals $\pi_{N C}(n) \equiv F(n)-n \underline{w}$. The firm's profit function in this non-binding setting equals $\tilde{\pi}(n) \equiv F(n)-n \tilde{w}(n)$. We denote the bargaining power of the union by $\phi \in[0,1]$.

We model first-contract mediation as an extensive-form bargaining game. The mediation technology proceeds as a finite sequence of pairwise bargaining sessions over wages between the union and the firm in the presence of a mediator. Bound by the replication principle, the mediator does not capture any rents on the bargaining table. Essential for our analysis is the assumption that the outcomes of these mediation sessions are nonbinding, i.e. there is no capability to bind either party to future wage and employment decisions. Hence, we allow the union and the firm to engage in an arbitrary number of pairwise negotiations prior to production in which the union can costlessly re-open negotiations over the individual wages of its employed members with the firm and vice versa. Such a renegotiation occurs when any number of dissatisfied workers decide to quit and/or the firm decides to dismiss any number of individual workers. We allow the union to renegotiate with the firm on behalf of all remaining employees. An employee who returns to the external labor market can never re-enter the firm and stays a union member earning the reservation wage. In Section 3.2, we assume that employees are irreplaceable. We relax the irreplaceability assumption in Section 3.3. We assume riskneutral employees with individual utilities equal to wages. Union preferences are represented by a utilitarian objective function. We assume generalized Nash bargaining. The bargaining scope is negotiation over wages alone.

The mediation game is presented in Figure 1.

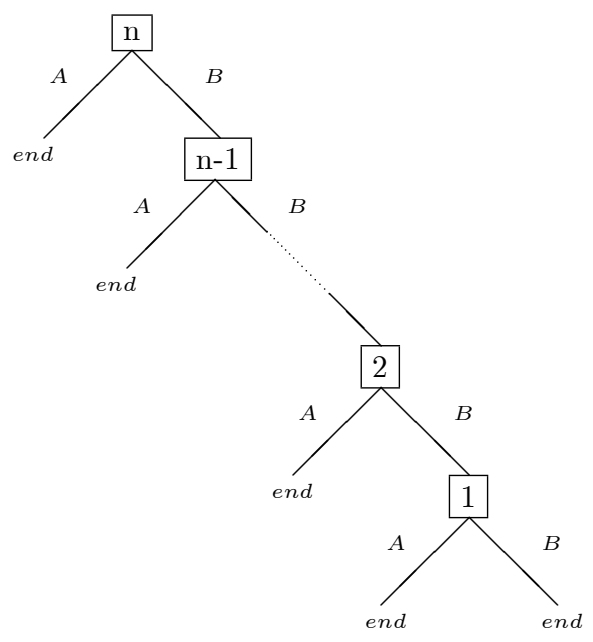

Figure 1: The mediation game.

Each mediation session is depicted by a box, representing the number of employees on which behalf the union is negotiating with the firm. In the first mediation session, the union represents $n$ employees. In each mediation session, either the union and the firm reach an agreement $(A)$, or negotiations break down $(B)$. Whenever an agreement is reached, the game ends. Whenever a mediation session ends in a breakdown, one randomly chosen employee exits the game forever, after which bargaining starts again between the firm and 
the union representing the remaining employees. ${ }^{2}$ At most $n$ mediation sessions can occur before the game terminates in which case all employees have dropped out following failed mediation sessions.

Within each mediation session, the mediator mimics the alternating-offer bargaining game of Binmore et al. (1986) in which there is an exogenous probability of breakdown following each rejected offer. Breakdown probabilities differ following a rejection by the firm or the union. The game is described as follows. Starting with the firm, the firm and the union alternate wage proposals. If a proposal is accepted, negotiations terminate. If a proposal is rejected, negotiations break down with probability $p_{f}$ if a rejection is made by the firm and with probability $p_{u}$ if a rejection is made by the union. When a breakdown does not occur, the rejecting party makes a counterproposal. Proposals are made until one is accepted or a breakdown occurs. There is no discounting. It is straightforward to demonstrate that every bargaining power $\phi \in[0,1]$ is consistent for some pair of probabilities $\left(p_{f}, p_{u}\right)$ in the following way:

$$
\phi=\frac{p_{f}\left(1-p_{u}\right)}{p_{f}\left(1-p_{u}\right)+p_{u}}
$$

We look for the limiting outcome as breakdown probabilities approach zero. Binmore et al. (1986) show that for such a bargaining session the generalized Nash bargaining solution emerges.

\subsection{An efficiency argument for first-contract mediation}

We are looking for the mediation contract that is $(i)$ non-wasteful, i.e. $i \tilde{w}(i)+\tilde{\pi}(i)=F(i)$ for all $i \leq n,(i i)$ stable, i.e. for any given bargaining power, neither the union nor the firm can respectively improve wages or profits in a pairwise renegotiation and (iii) incentive compatible with respect to $\underline{w}$, i.e. $\tilde{w}(i) \geq \underline{w}$ for all $i \leq n$ implying that the employees' outside option constraint is not violated.

Our main result is a powerful efficiency argument for first-contract mediation. It is stated in Proposition 1.

Proposition 1. First-contract mediation yields a Pareto-efficient outcome.

All proofs of the propositions are found in the Appendix.

We provide an intuitive interpretation for Proposition 1. The driving force behind the result is that equilibrium wages, profits and employment of our first-contract mediation setting are equivalent to the corresponding equilibrium outcomes of the binding EB setting. When a firm bargains with a union in a non-binding mediation setting over wages alone, the firm cannot anymore determine employment unilaterally afterwards. This is due to the stability requirement of the contract. Suppose that the union and the firm agree upon a wage $\tilde{w}\left(\tilde{n}^{*}\right)$. However, assume that $\max _{n} \tilde{\pi}(n)=n^{\prime}>\tilde{n}^{*}$. The firm chooses employment level $n^{\prime}$, after which the union and the firm want to renegotiate $\tilde{w}\left(n^{\prime}\right)$, contradicting that $\tilde{w}\left(\tilde{n}^{*}\right)$ was stable. In other words, although at the outset the union and the firm bargain only over wages in a non-binding mediation setting, they implicitly have to reach a binding agreement on wages and employment in the end. The latter is exactly the objective of union-firm bargaining in an EB framework.

The striking lesson that can be learned from this equivalence result is that starting from the RTM framework, a Pareto-efficient outcome can be obtained by introducing mediation, i.e. changing the contract setting from

\footnotetext{
${ }^{2}$ It is important to stress that the mediator does not impose that the number of workers must decrease by one after each failed negotiation session. The only reason why we model the mediation game in this way is to allow for the possibility that, at any moment prior to production, a dissatisfied worker quits voluntarily or a worker is laid off by the firm.
} 
binding to non-binding, instead of changing the bargaining scope from wages to wages and employment. This alternative route of reaching Pareto efficiency is absent in standard labor economics textbooks that advocate changing the framework from RTM to EB.

Proposition 1 allows to investigate whether the SZ overemployment result is robust to a change in the labor organization from the individual to the collective level. The answer is negative since the optimal level of employment in our setting coincides with the one of an NC firm. Hence, we obtain the following corollary.

Corollary 1. Due to unionization, the SZ overemployment result disappears under first-contract mediation.

\subsection{The role of a replacement pool}

Until now, we have assumed that employees are irreplaceable. Alternatively, the union could deploy its union members outside the firm to provide the firm with a finite ready-to-employ replacement pool. In what follows, we again assume that an employee who leaves the firm can never return to the firm and stays a union member earning the reservation wage. However, the firm can now immediately draw upon the replacement pool to substitute the latter. The question in terms of application is whether firms have such a replacement pool available. The answer is most likely affirmative when untrained or low-skilled employees are involved. It is well documented that for such employees, negotiations with the firm typically occur collectively rather than individually, making this setting most relevant.

Proposition 2 challenges the role of a replacement pool under first-contract mediation.

Proposition 2. The availability and the size of a finite replacement pool leaves the mediation contract unchanged.

We give an intuitive interpretation for Proposition 2. Suppose that for a given employment level $n$, the union and the firm agree upon a wage scheme that negatively depends on the size of the replacement pool. Consider $n$ employees and $\mathcal{N}-n$ unionized ready-to-employ workers. In this case, the firm wants to keep the replacement pool as large as possible in order to reduce the wage bill. However, the union has an incentive to deploy the replacement pool in order to increase the total sum of union members' wages. As a result, the wage scheme cannot be stable. A similar argument, where the incentives of the firm and the union are reversed, holds when the wage scheme depends positively on the replacement pool.

Propositions 1 \& 2 allow to answer the question whether the FG underemployment result is robust to a change in the labor organization from the individual to the collective level. The answer is negative since the presence of a replacement pool does not affect the wage-employment equilibrium and the latter coincides with the binding EB equilibrium. First-contract mediation proves immune to the insider-outsider problem of underhiring. Hence, we obtain the following corollary. ${ }^{3}$

Corollary 2. Due to unionization, the FG underemployment result disappears under first-contract mediation.

\footnotetext{
${ }^{3}$ Importantly, since the equivalence between our contract and the efficient bargaining contract is driven by the stability requirement, this equivalence would still hold if workers were risk-averse (risk-loving). In other words, risk-neutrality is not needed to obtain Proposition 1. However, as the Pareto-efficient contract lies on a negatively (positively) sloped contract curve, the optimal employment level no longer coincides with neoclassical employment, leading to underemployment (overemployment). As a result, without imposing risk neutrality, Corollaries $1 \& 2$ would no longer hold.
} 


\section{A cooperative characterization of first-contract mediation}

Since workers organize themselves in a union to negotiate with the firm, we can analyze our mediation setting as a cooperative game. The goal of this section is to provide different cooperative characterizations of our equilibrium wages and profits and show that they coincide with well-known solution concepts in cooperative game theory.

Consider the $(n+1)$-player cooperative game $(N, v)$, where $N=\{0,1, \ldots, n\}$ is the set of players in which we index the firm as 0 and the employees as the positive integers 1 to $n$. The mapping $v: 2^{|N|} \rightarrow \mathbb{R}$ represents the characteristic function, assigning to any possible coalition $S \subseteq N$ a real number $v(S)$ called the value of coalition $S$. The value of the empty coalition equals zero, i.e. $v(\emptyset)=0$. Any coalition $S$ excluding the firm does not have access to the firm's production process and obtains its outside option, i.e. $v(S)=|S| \underline{w}$ when $0 \notin S$. Any coalition $S$ including the firm engages in production, i.e. $v(S)=$ $F(|S|-1)$ when $0 \in S$. The value of the grand coalition equals $v(N)=F(|N|-1)=F(n)$. Stole and Zwiebel (1996a) demonstrate that if the firm's bargaining power equals $1 / 2$ (i.e. $1-\phi=\frac{1}{2}$ ), SZ wages and SZ profits respectively coincide with the Shapley values of the workers and the firm for this $(n+1)$-player cooperative game, i.e. $w_{S Z}\left(n^{*}\right)=S h_{1}(N, v)=\ldots=S h_{n}(N, v)$ and $\pi_{S Z}\left(n^{*}\right)=S h_{0}(N, v)$ respectively, where $S h_{i}(N, v)=\sum_{S \subseteq N \backslash\{i\}} \frac{|S| !(|N|-|S|-1) !}{|N| !}(v(S \cup\{i\})-v(S))$ for all $i \in N$.

\subsection{The 2-player cooperative game}

Before establishing a cooperative characterization of the mediation contract in the $(n+1)$-player cooperative game, we first consider the 2-player cooperative game $(\{0,1\}, v)$, denoting the firm as 0 and the union consisting of $n$ employees as 1. For this 2-player game, it holds that $v(\emptyset)=v(0)=0, v(1)=n \underline{w}$ and $v(0,1)=F(n)$.

Proposition 3 characterizes workers' wages and firm's profits under equal bargaining power.

Proposition 3. If the firm's bargaining power equals 1/2, then workers' wages equal the Shapley value of the union divided by the number of employees and the firm's profit equals its Shapley value.

Proposition 3 can be generalized for any bargaining power $\phi \in[0,1]$. Define a unanimity game $u_{S}$ as a game such that $u_{S}(T)=1$ if $S \subseteq T$ and $u_{S}(T)=0$ otherwise. It is well known that every coalitional game $(N, v)$ can be written as a linear combination of unanimity games in a unique way, i.e. $v=$ $\sum_{S \subset N} \lambda_{S}(v) u_{S}$. The coefficients $\lambda_{S}(v)$ are called unanimity coefficients of the game $(N, v)$ and are given by $\lambda_{S}(v)=\sum_{T \subseteq S}(-1)^{|S|-|T|} v(T)$. The weighted Shapley value for any coalitional game $(N, v)$ and weight vector $\left(\theta_{i}\right)_{i \in N}$ is then given by $S h_{i}(N, v, \theta)=\sum_{i \in S} \lambda_{S}(v) \frac{\theta_{i}}{\sum_{j \in S} \theta_{j}}$.

We obtain Proposition 4.

Proposition 4. Workers' wages equal the weighted Shapley value of the union divided by the number of employees and the firm's profit equals its weighted Shapley value for any weight vector $\theta=\left(\theta_{0}, \theta_{1}\right)$ where $\frac{\theta_{0}}{\theta_{0}+\theta_{1}}=1-\phi$ and $\frac{\theta_{1}}{\theta_{0}+\theta_{1}}=\phi$. 


\subsection{The $(n+1)$-player cooperative game}

The previous section allows for a characterization of equilibrium wages and profits in terms of (weighted) Shapley values. Returning to the $(n+1)$-player cooperative game $(N, v)$, we obtain an alternative characterization in terms of modified Shapley values, known as Owen values (Owen, 1977), that takes into account possible coalitional structures that may form between players. The standard textbook interpretation of the Shapley value is that of a queue of players, where each player is entering a room and is obtaining her marginal contribution to the coalition of players already present in the room. In case of the Shapley value, all queues are formed with equal probability and the Shapley value is precisely the expected marginal contribution to coalitions with respect to this random order of players. In contrast, the Owen value restricts the possible formation of queues according to the coalitional structure. We formally define a coalitional structure $B=\left\{S_{1}, \ldots, S_{m}\right\}$ which partitions $N$ into $m$ disjoint subsets. Let $\omega$ be a permutation on $N$ and let $\Omega$ be the set of all permutations on $N$. Define $\Omega(B)$ as the subset of $\Omega$, which includes only the orders in which players of the same component of $B$ appear successively; i.e. $\Omega(B)=\left\{\omega \in \Omega:\right.$ if $i, j \in S_{k}$ and $\omega(i)<\omega(l)<\omega(j)$, then $\left.l \in S_{k}\right\}$. Then, the Owen value assigns to each player her expected marginal contribution to the coalition of preceding players with respect to a uniform distribution over the set of orders in $\Omega(B)$; i.e. $O_{i}(B, v)=\frac{1}{|\Omega(B)|} \sum_{\omega \in \Omega(B)}\left(v\left(P_{i}^{\omega} \cup i\right)-v\left(P_{i}^{\omega}\right)\right)$ for all $i \in N$, where $P_{i}^{\omega}=\{j \in N, \omega(j)<\omega(i)\}$.

In our framework, $\bar{B}=\left\{S_{1}, S_{2}\right\}$ where $S_{1}=\{0\}$ is containing the firm, and $S_{2}=\{1, \ldots, n\}$ is containing the workers.

We obtain Proposition 5.

Proposition 5. If the firm's bargaining power equals 1/2, then workers' wages and the firm's profit equal their Owen values in the cooperative game with coalitional structure $\bar{B}$.

Proposition 5 can be generalized for any bargaining power $\phi \in[0,1]$ in terms of "weighted" Owen values in the cooperative game with coalitional structure $\bar{B}$. However, to the best of our knowledge, the latter solution concept is not yet defined in the literature (for any coalitional structure $B$ ) and doing so goes beyond the scope of this paper. Nevertheless, for our specific coalitional structure $\bar{B}$, an elegant interpretation can be given which resembles Owen (1968)'s original interpretation of the weights of the weighted Shapley value as a measure of players' delay to reach the grand coalition. Owen showed that the introduction of weights amounts to distorting the equal probabilities with which queues form in the following way: the higher the weight of a player, the higher the probability of the queues in which this player arrives the last. In our setting with coalitional structure $\bar{B}$ and the firm's bargaining power equal to $1 / 2$, the firm ends up at either end of the order with equal probability, yielding the Owen value of $1 / 2$ times the firm's marginal contribution to the grand coalition (remember that the marginal contribution of the firm entering first equals zero). Generalizing, with coalitional structure $\bar{B}$ and the firm's bargaining power equal to $(1-\phi)$, the firm's bargaining power exactly reflects the probability that the firm enters the last in the order of players, yielding the "weighted" Owen value of $(1-\phi)$ times the firm's marginal contribution to the grand coalition.

\section{Conclusion}

British Columbia's use of mediation to resolve negotiations of a first contract in a newly unionized workplace can provide important insights for labor law legislation reforms in the US. The cornerstone of BC's firstcontract model is non-binding recommendations regarding the terms of the collective agreement under the 
mediator's objective to replicate conventional bargaining as close as possible. We show that the outcome of first-contract mediation is Pareto efficient and coincides with the outcome of the binding efficient bargaining framework. The availability and the size of a finite replacement pool leave the mediation contract unchanged. These findings allow to conclude that the Stole and Zwiebel (1996a, 1996b) overemployment result and the de Fontenay and Gans (2003) underemployment result disappear under unionization. Hence, the welfare gains associated with the optimal allocation of labor under first-contract mediation are sizeable.

An evident continuation is to explore decisions under first-contract mediation regarding, among others, hiring, technological choice, organizational design and work stoppages. Furthermore, if data on labor contract specificities obtained under mediation were available, our result that the mediation contract is Pareto efficient would provide the foundation of an original test of Pareto efficiency in the empirical collective bargaining literature. An interesting extension of our framework, following Horn and Wolinsky (1988), is to introduce worker heterogeneity and to study the formation of multi-union patterns, possibly exploited by the firm to its advantage.

Recently, within a dynamic framework, a number of studies have introduced individual wage bargaining in a search and matching economy (e.g. Cahuc and Wasmer, 2001; Cahuc et al.; 2008; Helpman et al., 2008; Mortensen, 2009). Bauer and Lingens (2010) are the first to analyze and compare the wage-employment equilibrium under collective and individual wage bargaining in a large firm search model in an attempt to answer the question whether collective wage bargaining can restore efficiency in the labor market or not. Under the assumption that collective wage bargaining takes the form of all employees delegating the wage negotiation to a representative worker and deciding jointly whether to work or not, they show that both collective and individual wage bargaining regimes deliver inefficient allocations. Whether these conclusions also hold under non-binding mediation, allowing employees in a unionized firm to make individual employment decisions, still remains an open question.

\section{References}

[1] Bauer, Christian, and Jörg Lingens. 2010. "Individual vs. collective bargaining in the large firm search model." Munich Discussion Paper 2010-8.

[2] Binmore, Kenneth, Ariel Rubinstein, and Asher Wolinsky. 1986. "The Nash bargaining solution in economic modeling." Rand Journal of Economics, 17(2): 176-188.

[3] Cahuc, Pierre, and Etienne Wasmer. 2001. "Does intrafirm bargaining matter in the large firm's matching model?" Macroeconomic Dynamics, 5(5): 742-747.

[4] Cahuc, Pierre, François Marque, and Etienne Wasmer. 2008. "A theory of wages and labor demand with intrafirm bargaining and matching frictions." International Economic Review, 49(3): 943972.

[5] Cooke, William. 1985. "The failure to negotiate first contracts: Determinants and policy implications." Industrial and Labor Relations Review, 38(2): 163-178.

[6] de Fontenay, Catherine C., and Joshua S. Gans. 2003. "Organizational design and technology choice under intrafirm bargaining: Comment." American Economic Review, 93(1): 448-455. 
[7] Ferguson, John-Paul, and Thomas Kochan. 2008. "Sequential failures in workers' right to organize." mimeo.

[8] Johnson, Susan J.T. 2010. "First contract arbitration: Effects on bargaining and work stoppages." Industrial and Labor Relations Review, 63(4): 585-605.

[9] Helpman, Elhanan, Oleg Itskhoki, and Stephen J. Redding. 2008. "Wages, unemployment and inequality with heterogeneous firms and workers." NBER Working Paper 14122.

[10] Horn, Henrik, and Asher Wolinsky. 1988. "Worker substitutability and patterns of unionisation." Economic Journal, 98(391): 484-497.

[11] McDonald, Ian M., and Robert M. Solow. 1981. "Wage bargaining and employment." American Economic Review, 71(5): 896-908.

[12] Mortensen, Dale T. 2009. "Wage dispersion in the search and matching model with intra-firm bargaining." NBER Working Paper 15033.

[13] Myerson, Roger B. 1980. "Conference structures and fair allocation rules." International Journal of Game Theory, 9(3): 169-182.

[14] Nickell, Stephen J., and Matthew Andrews. 1983. "Unions, real wages and employment in Britain 1951-79." Oxford Economic Papers, 35(supplement): 183-205.

[15] Owen, Guillermo. 1968. "A note on the Shapley value." Management Science, 14(11): 731-732.

[16] Owen, Guillermo. 1977. "Values of games with a priori unions." In Mathematical economics and game theory; Essays in Honor of Oskar Morgenstern, ed. Rudolph Henn and Otto Moeschlin. New York: Springer-Verlag.

[17] Stole, Lars A., and Jeffrey Zwiebel. 1996a. "Intrafirm bargaining under non-binding contracts." Review of Economic Studies, 63(3): 375-410.

[18] Stole, Lars A., and Jeffrey Zwiebel. 1996b. "Organizational design and technology choice under intrafirm bargaining." American Economic Review, 86(1): 195-222.

[19] Vipond, Melanie. 2011. "First contract arbitration: Evidence from British Columbia of the significance of mediators' non-binding recommendations." Labor Law Journal, 62(3): 1-34.

[20] Westermark, Andreas. 2003. "Bargaining, binding contracts, and competitive wages." Games and Economic Behavior, 43(2): 296-311. 


\section{Appendix : Proofs of propositions}

\section{Proof of proposition 1}

First-contract mediation yields a Pareto-efficient outcome.

Proof. It is sufficient to show that equilibrium wages and profits under first-contract mediation are equivalent to equilibrium wages and profits under efficient bargaining. Under utilitarian union preferences, the union's payoff when there are $n$ employees equals $n \tilde{w}(n)+(\mathcal{N}-n) \underline{w}$. The union's payoff when there are $n-1$ employees equals $(n-1) \tilde{w}(n-1)+(\mathcal{N}-n+1) \underline{w}$. Hence, the union's net gain from reaching a bargaining agreement equals $n \tilde{w}(n)-(n-1) \tilde{w}(n-1)-\underline{w}$. The firm's net gain from reaching a bargaining agreement equals $\tilde{\pi}(n)-\tilde{\pi}(n-1)$. The outcome of the bargaining is the generalized Nash solution to

$$
\max _{\tilde{w}}[n \tilde{w}(n)-(n-1) \tilde{w}(n-1)-\underline{w}]^{\phi}[\tilde{\pi}(n)-\tilde{\pi}(n-1)]^{1-\phi}
$$

We derive the equilibrium contract inductively over the number of employees. Consider the case where only one employee is present. Let $F(0)=0$. From the first-order condition of the logarithm of Eq. (1), we obtain

$$
\begin{gathered}
\tilde{\pi}(1)=\frac{1-\phi}{\phi}(\tilde{w}(1)-\underline{w}) \\
\Leftrightarrow \Delta F(1)-\tilde{w}(1)=\frac{1-\phi}{\phi}(\tilde{w}(1)-\underline{w}) \\
\Leftrightarrow \tilde{w}(1)=\phi \Delta F(1)+(1-\phi) \underline{w}
\end{gathered}
$$

Note that $\tilde{w}(1)$ is incentive compatible by assumption. Now consider the case where two employees are present. We obtain

$$
\begin{gathered}
\tilde{\pi}(2)-\tilde{\pi}(1)=\frac{1-\phi}{\phi}(2 \tilde{w}(2)-\tilde{w}(1)-\underline{w}) \\
\Leftrightarrow \Delta F(2)-2 \tilde{w}(2)+\tilde{w}(1)=\frac{1-\phi}{\phi}(2 \tilde{w}(2)-\tilde{w}(1)-\underline{w}) \\
\Leftrightarrow \tilde{w}(2)=\frac{\phi}{2} \Delta F(2)+\frac{1}{2} \tilde{w}(1)+\frac{(1-\phi)}{2} \underline{w} \\
\Leftrightarrow \tilde{w}(2)=\frac{\phi}{2}[\Delta F(2)+\Delta F(1)]+(1-\phi) \underline{w}
\end{gathered}
$$

Note that $\tilde{w}(2)$ is incentive compatible by assumption. Generalizing the above argument over any $n$ by induction, we obtain as the solution to the first-order difference equation above the following expressions for $\tilde{w}(n)$ and $\tilde{\pi}(n)$ :

$$
\tilde{w}(n)=\frac{\phi}{n} \sum_{i=1}^{n} \Delta F(i)+(1-\phi) \underline{w}
$$

and

$$
\tilde{\pi}(n)=(1-\phi)\left[\sum_{i=1}^{n} \Delta F(i)-n \underline{w}\right]
$$

Eqs. (2) and (3) easily rewrite when directly using the production function rather than the marginal products:

$$
\tilde{w}(n)=\frac{\phi}{n} F(n)+(1-\phi) \underline{w}
$$

and

$$
\tilde{\pi}(n)=(1-\phi)[F(n)-n \underline{w}]=(1-\phi) \pi_{N C}(n)
$$


Note that $\tilde{w}(n)$ is incentive compatible by assumption. ${ }^{4}$ From Eq. (5), it follows that the optimal employment level in our setting, denoted by $\tilde{n}^{*}$, coincides with the optimal employment level of the neoclassical firm, denoted by $n_{N C}^{*}$.

Under EB, the outcome of the bargaining is the generalized Nash solution to

$$
\max _{w, n}[n(w-\underline{w})]^{\phi}[\pi(n)]^{1-\phi}
$$

Maximization of Eq. (6) with respect to the wage and employment gives the following two first-order conditions respectively:

$$
\begin{gathered}
w_{E B}(n)=(1-\phi) \underline{w}+\phi \frac{F(n)}{n} \\
w_{E B}(n)=\Delta F(n)+\phi\left(\frac{F(n)-\Delta F(n) n}{n}\right)
\end{gathered}
$$

Solving Eqs. (7) and (8) simultaneously gives the expression for the contract curve: $\Delta F(n)=\underline{w}$. Hence, the optimal level of employment under risk-neutral efficient bargaining, denoted $n_{E B}^{*}$, coincides with $n_{N C}^{*}$ and, as we just showed, with $\tilde{n}^{*}$. From Eqs. (4) and (7), it follows that $\tilde{w}\left(\tilde{n}^{*}\right)=w_{E B}\left(n_{E B}^{*}\right)$. As a result, $\tilde{\pi}\left(\tilde{n}^{*}\right)=\pi_{E B}\left(n_{E B}^{*}\right)$.

\section{Proof of proposition 2}

The availability and the size of a finite replacement pool leaves the mediation contract unchanged.

Proof. It is sufficient to show that the equilibrium wage in a non-binding collective bargaining setting is not affected by the availability and the size of a replacement pool. Denote the employee's wage by $\tilde{w}_{\mathcal{N}-n}(n)$ where the subscript indicates the number of unionized ready-to-employ workers outside the firm and the number in parentheses indicates the number of employees. Similarly, the firm's profit equals $\tilde{\pi}_{\mathcal{N}-n}(n)$. The union's payoff in case the firm does not draw upon the replacement pool equals $n \tilde{w}_{\mathcal{N}-n}(n)+(\mathcal{N}-n) \underline{w}$. The union's payoff in case the firm replaces an employee equals $n \tilde{w}_{\mathcal{N}-n-1}(n)+(\mathcal{N}-n) \underline{w}$. Hence, the union's net gain from reaching a bargaining agreement equals $n\left(\tilde{w}_{\mathcal{N}-n}(n)-\tilde{w}_{\mathcal{N}-n-1}(n)\right)$. The firm's net gain from reaching a bargaining agreement equals $\tilde{\pi}_{\mathcal{N}-n}(n)-\tilde{\pi}_{\mathcal{N}-n-1}(n)$. The outcome of the bargaining is the generalized Nash solution to

$$
\max _{\tilde{w}}\left[n\left(\tilde{w}_{\mathcal{N}-n}(n)-\tilde{w}_{\mathcal{N}-n-1}(n)\right)\right]^{\phi}\left[\tilde{\pi}_{\mathcal{N}-n}(n)-\tilde{\pi}_{\mathcal{N}-n-1}(n)\right]^{1-\phi}
$$

From the first-order condition of the logarithm of Eq. (9), we obtain

$$
\begin{gathered}
\tilde{\pi}_{\mathcal{N}-n}(n)-\tilde{\pi}_{\mathcal{N}-n-1}(n)=\frac{1-\phi}{\phi} n\left(\tilde{w}_{\mathcal{N}-n}(n)-\tilde{w}_{\mathcal{N}-n-1}(n)\right) \\
\Leftrightarrow n\left(\tilde{w}_{\mathcal{N}-n-1}(n)-\tilde{w}_{\mathcal{N}-n}(n)\right)=\frac{1-\phi}{\phi} n\left(\tilde{w}_{\mathcal{N}-n}(n)-\tilde{w}_{\mathcal{N}-n-1}(n)\right) \\
\Leftrightarrow \tilde{w}_{\mathcal{N}-n}(n)=\tilde{w}_{\mathcal{N}-n-1}(n)
\end{gathered}
$$

\footnotetext{
${ }^{4}$ If $\tilde{w}(n) \geq \underline{w}$, it cannot happen that $\tilde{w}(i)<\underline{w}$ for some $i<n$ when the firm optimally chooses its input level and the underlying neoclassical profit function is quasi-concave. Furthermore, our analysis shows that it is never optimal for the firm to hire workers beyond the point where $\tilde{w}(n)=\underline{w}$. Nevertheless, beyond this employment level, wages in our bargaining game would be given by $\underline{w}$ and not by $\tilde{w}(n)<\underline{w}$.
} 
From induction over the number of unionized ready-to-employ workers, we obtain that $\tilde{w}_{\mathcal{N}-n}(n)=\tilde{w}_{\mathcal{N}-n-1}(n)=$ $\ldots=\tilde{w}_{1}(n)=\tilde{w}_{0}(n)$. It is easy to check that the result holds for any number of employees, i.e. $\tilde{w}_{\mathcal{N}-i}(i)=$ $\tilde{w}_{0}(i)$ for $i \in\{1, \ldots, n\}$.

\section{Proof of proposition 3}

If the firm's bargaining power equals 1/2, then workers' wages equal the Shapley value of the union divided by the number of employees and the firm's profit equals its Shapley value.

Proof. The proof proceeds by contradiction. Suppose that $\tilde{\pi}(n)=\frac{1}{2}(F(n)-n \underline{w})$ and $n \tilde{w}(n)=\frac{1}{2}(F(n)+n \underline{w})$ are not the respective Shapley values of the firm and the union in the cooperative game $(\{0,1\}, v)$. Then, following Myerson (1980), at least one of the following two conditions must be violated: $(i)$ Balanced contributions: $S h_{0}(\{0,1\}, v)-S h_{0}(\{0\}, v)=S h_{1}(\{0,1\}, v)-S h_{1}(\{1\}, v)$ or $(i i)$ Efficiency: $S h_{0}(\{0,1\}, v)+$ $S h_{1}(\{0,1\}, v)=v(0,1)$. It is straightforward that condition $(i i)$ is satisfied. Since $S h_{0}(\{0\}, v)=0$ and $S h_{1}(\{1\}, v)=n \underline{w}$, it follows that condition $(i)$ is also satisfied, thereby contradicting that $\tilde{\pi}(n)$ and $n \tilde{w}(n)$ are not the Shapley values of the firm and the union in the cooperative game $(\{0,1\}, v)$.

\section{Proof of proposition 4}

Workers' wages equal the weighted Shapley value of the union divided by the number of employees and the firm's profit equals its weighted Shapley value for any weight vector $\theta=\left(\theta_{0}, \theta_{1}\right)$ where $\frac{\theta_{0}}{\theta_{0}+\theta_{1}}=1-\phi$ and $\frac{\theta_{1}}{\theta_{0}+\theta_{1}}=\phi$.

Proof. In our setting, $\lambda_{\{0\}}(v)=0, \lambda_{\{1\}}(v)=n \underline{w}$ and $\lambda_{\{0,1\}}(v)=F(n)-n \underline{w}$. When $\theta=\left(\theta_{0}, \theta_{1}\right)$ where $\frac{\theta_{0}}{\theta_{0}+\theta_{1}}=1-\phi$ and $\frac{\theta_{1}}{\theta_{0}+\theta_{1}}=\phi$, the reader can check that $S h_{0}(N, v, \theta)=(1-\phi)(F(n)-n \underline{w})=\tilde{\pi}(n)$ and $S h_{1}(N, v, \theta)=n \underline{w}+\phi(F(n)-n \underline{w})=\phi F(n)+(1-\phi) n \underline{w}=n \tilde{w}(n)$.

\section{Proof of proposition 5}

If the firm's bargaining power equals 1/2, then workers' wages and the firm's profit equal their Owen values in the cooperative game with coalitional structure $\bar{B}=\{\{0\},\{1, \ldots, n\}\}$.

Proof. First, consider the firm. Note that, given the coalitional structure $\bar{B}$, the firm enters either first or last in the order of players, implying that $|\Omega(\bar{B})|=2 n$ !. The marginal contribution of the firm entering first equals 0 , the marginal contribution of the firm entering last equals $F(n)-n \underline{w}$. Hence, $O_{0}(\bar{B}, v)=$ $\frac{n !}{2 n !}(F(n)-n \underline{w})=\frac{1}{2}(F(n)-n \underline{w})=\tilde{\pi}(n)$. The result for the workers' wages follows by noting that $(i)$ the cooperative game among workers when the firm is absent is inessential, implying that $O_{i}(\bar{B}, v)=O_{j}(\bar{B}, v)$ for all $i, j \in S_{2}$ and that (ii) Owen values satisfy efficiency with respect to the grand coalition, implying that $\sum_{i \in N} O_{i}(\bar{B}, v)=v(N)$. Hence, we obtain, for all $i \in S_{2}, O_{i}(\bar{B}, v)=\frac{v(N)-O_{0}(\bar{B}, v)}{n}=\frac{F(n)-\frac{1}{2}(F(n)-n \underline{w})}{n}=$ $\frac{1}{2 n} F(n)-\frac{1}{2} \underline{w}=\tilde{w}(n)$. 